\title{
Advanced Gastric Neuroendocrine Carcinoma
}

National Cancer Institute

\section{Source}

National Cancer Institute. Advanced Gastric Neuroendocrine Carcinoma. NCI Thesaurus. Code C156683.

A gastric neuroendocrine carcinoma that has spread extensively to other anatomic sites or is no longer responding to treatment. 